\title{
Brain Imaging of Taste Perception in Obesity: a Review
}

\author{
Christopher Kure Liu ${ }^{1} \cdot$ Paule Valery Joseph ${ }^{2}$ - Dana E. Feldman ${ }^{1} \cdot$ Danielle S. Kroll ${ }^{1}$ - Jamie A. Burns ${ }^{1} \cdot$ Peter Manza $^{1}$. \\ Nora D. Volkow ${ }^{1,3} \cdot$ Gene-Jack Wang ${ }^{1}$
}

Published online: 4 April 2019

(C) The Author(s) 2019

\begin{abstract}
Purpose of Review We summarize neuroimaging findings related to processing of taste (fat, salt, umami, bitter, and sour) in the brain and how they influence hedonic responses and eating behaviors and their role in obesity.

Recent Findings Neuroimaging studies in obese individuals have revealed alterations in reward/motivation, executive control/ self-regulation, and limbic/affective circuits that are implicated in food and drug addiction. Psychophysical studies show that sensory properties of food ingredients may be associated with anthropometric and neurocognitive outcomes in obesity. However, few studies have examined the neural correlates of taste and processing of calories and nutrient content in obesity.

Summary The literature of neural correlated of bitter, sour, and salty tastes remains sparse in obesity. Most published studies have focused on sweet, followed by fat and umami taste. Studies on calorie processing and its conditioning by preceding taste sensations have started to delineate a dynamic pattern of brain activation associated with appetition. Our expanded understanding of taste processing in the brain from neuroimaging studies is poised to reveal novel prevention and treatment targets to help address overeating and obesity.
\end{abstract}

Keywords Obesity $\cdot$ Neuroimaging $\cdot$ Taste $\cdot$ Gustation $\cdot$ Eating $\cdot$ Nutrition

\section{Introduction}

The prevalence of obesity in the United States has risen significantly since the 1980s [1]. Between 2015 and 2016, 4 in 10 Americans were considered obese, which is defined in the USA as having a body mass index (BMI) over 30, and over 28 in China $[2 \cdot \bullet, 3]$. Obesity-related diseases are some of the leading causes of preventable death in the USA and world, so it is paramount to understand their underlying causes $[4,5]$.

This article is part of the Topical Collection on Nutrition and the Brain

Gene-Jack Wang

gene-jack.wang@nih.gov

Christopher Kure Liu

christopher.kureliu@nih.gov

Paule Valery Joseph

paule.joseph@nih.gov

Dana E. Feldman

dana.feldman@nih.gov

Danielle S. Kroll

danielle.kroll@nih.gov

Jamie A. Burns

jamie.burns@nih.gov
With the increasing presence of refined sugars, salts, and fats and the high calorie content in processed foods, individual, neurobiological differences in taste perception and conditioning to these ingredients may contribute to increased risk for obesity $[6,7,8 \cdot, 9-11]$. To that end, neuroimaging and psychophysical studies could reveal neural mechanisms of aberrant eating in obesity.

Sensory systems, particularly taste and smell, significantly affect food selection and consumption. Taste sensation occurs

Peter Manza

peter.manza@nih.gov

Nora D. Volkow

nvolkow@nida.nih.gov

1 Laboratory of Neuroimaging, National Institute on Alcohol Abuse and Alcoholism, National Institutes of Health, 10 Center Dr, Rm B2L124, Bethesda, MD 20892-1013, USA

2 Sensory Science and Metabolism Unit, Biobehavioral Branch, National Institute of Nursing Research, National Institutes of Health, 31 Center Drive, Rm 5B03, Bethesda, MD 20892-2178, USA

3 National Institute on Drug Abuse, National Institutes of Health, 6001 Executive Blvd., Suite 5274, Bethesda, MD 20892-9581, USA 
when chemosensory stimuli (e.g., salt) interact with taste receptor cells (TRCs) in the tongue. In addition to the five basic tastes (sweet, salty, bitter, sour, and umami), which are chemotopically organized in the human gustatory cortex, fat is considered a sixth taste modality [12-16]. Taste information is sent to the brain's feeding and reward systems, which affect eating behaviors and taste preferences $[17,18]$. Hedonic eating, or food consumption for pleasure but not hunger, when excessive, can lead to weight gain and obesity disrupting processing of taste input to the brain and enhancing conditioning to taste, smell, and calorie processing [11, 19-23]. When it comes to smell, olfactory ablation protects against dietinduced obesity in preclinical studies, suggesting that smell modulates taste perception to influence food intake [24]. Additionally, alterations in reward, executive control and affective circuits, and in homeostatic signals are risk factors for excessive hedonic eating [25]. Aberrant dopamine signaling akin to that observed in addiction is associated with these disruptions, which may further contribute to compensatory reward-seeking behaviors like overeating [26-28].

Psychophysical methods (e.g., whole mouth sip and spit of tastants) have been extensively used to study taste. However, advances in neuroimaging procedures and chemosensory stimulus delivery techniques (e.g., tastant delivery during brain imaging sessions) have provided novel insight into central mechanisms underlying taste and hedonic eating. Brain responses to food stimuli may differ in obese individuals compared to those without obesity, as illustrated in Fig. 1. Additionally, individuals with obesity show marked structural and functional brain-circuitry alterations [29-36].

Here, we review the impact of taste on neuroimaging outcomes regarding the hedonic aspects of eating in obesity, with a focus on the neural correlates of fat, umami, bitter, salty, and sour tastes across brain areas implicated in obesity, as outlined in Table 1. Although sweet is one of the basic tastes, the neural correlates of hedonic responses to sugar in obesity were recently reviewed so we do not discuss them here $[37,38]$. Further, evidence of compromised olfaction capacity in obesity exists [39, 40]. However, few studies have assessed brain activation patterns to smell in individuals with obesity [41-43]. The brain regions we focus on include the primary and secondary gustatory cortices. The primary gustatory cortex processes taste perception and comprises the anterior insula and frontal operculum. The secondary gustatory cortex, which comprises the orbitofrontal cortex (OFC) and medial prefrontal cortex (mPFC), integrates sensory properties of food to generate flavor and assigns saliency values [44].

\section{Fat Taste}

Palatable, high-fat foods contribute to increased risk for obesity [45]. Recently, orosensory fat perception was proposed as a primary taste that might regulate dietary fat consumption [13-16]. Although several taste receptors for fat exist, CD36, a scavenger receptor with an affinity for long chain fatty acids, is the most studied [13]. CD36 is expressed on the membrane of lingual TRCs and facilitates fatty acid uptake [46]. Preclinical CD36 knockout studies indicate that the receptor is necessary to establish fatty taste preferences [47]. Additionally, CD36 genetic variations have been associated with obesity in humans [13].

Recent neuroimaging studies in healthy volunteers investigated the brain's response to fatty stimuli. Several studies found that oral fat administration was associated with bloodoxygen-level dependent (BOLD) activation in the secondary gustatory cortex $[48,49]$. Support from source-localized electroencephalography (EEG) studies shows that consumption of high-fat relative to low-fat milk was associated with greater late positive potential amplitudes in OFC and hippocampus,

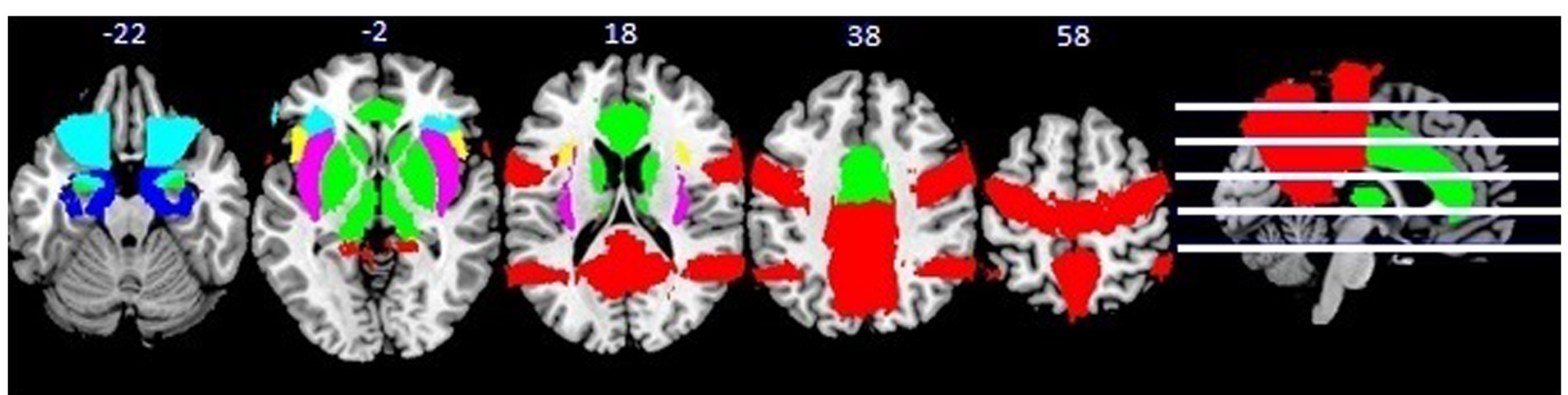

Fig. 1 Brain activation patterns (overweight and obese $>$ healthy controls) of taste modalities (bitter, salty, and fat) compiled from studies in Table 1. Red (fat taste): BOLD contrast (overweight $>$ healthy controls) to high-fat, high-sugar milkshake in right insula/operculum, precentral gyrus, angular gyrus, bilateral precuneus, posterior cingulate (Bohon et al., 2017). Green (bitter taste): BOLD contrast (obese > healthy controls) to quinine-hydrochloride solution in insula, ACC, OFC, amygdala, putamen, pallidum (Szalay et al. 2012). Blue (salty taste): $\left[{ }^{18} \mathrm{~F}-\mathrm{FDG}\right]$ glucose metabolism (overweight and obese $>$ healthy controls) following sodium chloride solution in insula, OFC, parahippocampus (Li et al., 2017). Pink: Overlapping brain activation in insula in response to fat, salty, and bitter tastes. Turquoise: Overlapping brain activation in OFC in response to bitter and salty tastes. Yellow: Overlapping brain activation patterns in response to fat and bitter tastes the numbers above the brain slices indicate the $\mathrm{Z}$ coordinate in MNI space 
Table 1 Neural correlates of taste information processing in obese and overweight populations

\begin{tabular}{lll}
\hline Authors (year) $\quad$ Study group & Imaging task & $\begin{array}{l}\text { Neural correlates in obese and } \\
\text { overweight populations vs } \\
\text { healthy controls }\end{array}$ \\
\hline
\end{tabular}

Fat taste

Bohon et al. (2017)

$N=10$ healthy-weight children (BMI between 5 th and 85 th percentile)

$N=8$ overweight children (BMI greater than 85 th percentile)

Babbs et al. (2013)

$N=12$ normal-weight adults $(\mathrm{BMI}<25)$

$N=13$ overweight adults $(\mathrm{BMI} \geq 25)$

Umami taste

Magerowski et al. (2018) $N=30$ healthy-weight women (mean BMI: $22.1 \pm 0.4$ )

$N=30$ Three Factor Eating

Questionnaire at baseline

Randomization into buffet meal test or fMRI paradigm after MSG+/MSGbroth consumption

$N=15$ buffet meal tests

$N=14$ fMRI paradigm

Salty taste

Li et al. (2017)

Hardikar et al. (2018)

Bitter taste

Szalay et al. (2012)

Green et al. (2015)
$N=156$ healthy-weight participants

$N=100$ overweight participants $(B M I \geq 25)$ and participants with obesity (BMI $\geq 28)$

$N=30$ healthy-weight participants (BMI between 18.5 and 25)

$N=25$ participants with obesity (BMI > 30)

$N=12$ healthy-weight participants (mean BMI 21.42 \pm 2.53 )

$N=12$ participants with obesity (mean BMI: $34.05 \pm 3.35$ )

$N=15$ healthy-weight participants (mean BMI: 25.25 \pm 3.3 )

$N=16$ individuals with abdominal obesity (mean BMI: $39.26 \pm 2.2$ )
Visual food cue presentation of either chocolate milkshake or water

Tastant delivery of either chocolate milkshake or tasteless solution

(3 T fMRI)

Tastant delivery of either milkshake or tasteless solution

Self-report measures of impulsivity, willingness to work for food, and pleasantness (rated during scan) of milkshake taste

(3 T fMRI)

Visual food cue presentation that subjects rated on health and appetitiveness.

Choice selection followed visual food cue presentation where subjects presented with two images of food and told to choose the food they would "rather eat right now"

(3 T fMRI)

Buccal administration of sodium chloride stimulus solution $40 \mathrm{~min}$ prior to scan

$\left(\left[{ }^{18} \mathrm{~F}-\mathrm{FDG}\right]-\mathrm{PET} / \mathrm{CT}\right)$

Tastant delivery of suprathreshold sucrose or sodium chloride solution (EEG)

Tastant delivery of either quinine hydrochloride or tasteless distilled water

(3 T fMRI)

Tastant delivery of either caffeine or sucrose solutions (3 T fMRI)
Greater BOLD contrast (milkshake $>$ tasteless) in right insula, operculum, precentral gyrus, angular gyrus, bilateral precuneus, and posterior cingulate

Greater BOLD contrast (milkshake $>$ tasteless) in ventral putamen

Lower BOLD contrast (milkshake $>$ tasteless) in caudate nucleus

Greater BOLD contrast (MSG+> MSG-) in left DLPFC and lower BOLD contrast (MSG+> MSG-) in cerebellum, precuneus, and fusiform gyrus in women with high eating disinhibition

*note: all subjects are healthy volunteers

Greater glucose metabolism in insula, $\mathrm{OFC}$, and parahippocampus

Weaker and shorter-latency gustatory-evoked potential to sodium chloride

Greater brain activation in ACC, gustatory cortex, OFC, amygdala, putamen, and pallidum

Greater brain activation in pre- and post- central gyri, fusiform gyrus, insula, lentiform nucleus, putamen, and frontopolar cortex to caffeine and sucrose

Sour taste

which reflected calorie content assessment of milk [50]. However, compared to sugar, fat may affect brain reward regions differently. For example, high fat relative to high-sugar milkshakes elicited greater BOLD responses in caudate and somatosensory regions, but no significant bilateral insular changes, whereas high sugar relative to high-fat milkshakes elicited greater BOLD responses in putamen and gustatory regions and increased bilateral insula activation [51]. Based on these findings, it appears that fat might affect brain reward circuitry differently than sugar.

Further, obesity is associated with reward circuitry dysregulations, which is reflected in brain response to fat $[30,52,53]$. For instance, overweight compared to healthyweight children showed greater BOLD responses in right 
insula, operculum, bilateral precuneus, and posterior cingulate cortex following milkshake consumption [9]. Additionally, following milkshake consumption, overweight compared to healthy-weight adults showed greater BOLD responses in ventral putamen and rolandic operculum but lower caudate BOLD responses, which were associated with higher impulsivity [10]. This suggests a mechanism for compulsive eating [10]. However, these milkshakes had high sugar and fat content, making it unclear whether these brain response patterns reflect an interaction between the tastants [9, 10].

Brain responses to fat in healthy volunteers can also be used to elucidate eating patterns and BMI gain. Eldeghaidy et al. [54] showed that amygdala BOLD response to a fatty stimulus is attenuated after a high-fat meal compared to water intake. This suggests that satiety from a high-fat meal reduces the reward response to fat. Moreover, reduced BOLD response to a high-fat, low-sugar milkshake relative to a tasteless solution in the pre-supplementary motor area, a region critical for inhibitory control, predicted BMI gain in healthy volunteers [55]. Similar studies should be replicated in individuals with obesity in order to understand how these processes differ between individuals with and without obesity.

\section{Salty Taste}

Excess dietary salt has been linked to obesity and its comorbidities [56-58]. Altered salt perception may be a risk factor for, or a result, of obesity, as altered salt taste perception has been reported in obese individuals by some investigators but not by others [58-62]. Salt taste is generated by the salt-sensitive epithelial sodium channel $(\mathrm{ENaC})$ and transient receptor potential cation channel subfamily V member 1 (TRPV1) [63-65]. While $\mathrm{ENaC}$ regulates appetitive responses to low salt concentrations, TRPV1 regulates aversive responses to high salt concentrations in part via bitter and sour TRCs [66-68]. This concentration-dependent response helps maintain optimal sodium balance and coincides with a negative association between salt taste intensity and hedonic ratings [69-71].

Functional magnetic resonance imaging (fMRI) studies demonstrate that salty tastes engage various brain regions, including the frontal operculum, amygdala, OFC, middle cingulate cortex, thalamus, pre- and postcentral gyrus, and dorsolateral prefrontal cortex (DLPFC) [72, 73]. These regions modulate reward, taste processing, and executive control in eating. For example, increased activity in the left DLPFC, a region implicated in executive function, has been associated with improved self-control during food choice selection [74-77]. These regions also encode salt taste intensity: $\left[\mathrm{H}_{2}{ }^{15} \mathrm{O}\right]$-PET (positron-emission tomography), which measures cerebral blood flow, and fMRI studies reveal that sodium chloride in both highly concentrated, aversive levels and low, non-aversive levels engages the amygdala and OFC [72, 78].
For example, the middle insula and amygdala are increasingly engaged as sodium concentrations increase and hedonic ratings decrease [79]. Thus, a range of salt intensities recruit similar circuitry despite varied subjective responses. Additionally, salt taste intensity modulates the strength of insular-thalamic effective connectivity and is negatively associated with hedonic ratings, suggesting a mechanism for aversion to high salt intensities [68, 69].

Whether salt taste perception is different in obesity remains uncertain due to mixed psychophysical findings. Several studies showed no significant salt taste sensitivity differences between individuals with and without obesity $[61,62]$. In studies that report differences, some studies show higher salt sensitivity in obese individuals compared to those without obesity [80, 81]. Yet, other studies report lower salt sensitivity in obese individuals compared to those without obesity $[8 \bullet, 82,83]$. Additionally, studies on salt taste preferences have yielded mixed results in individuals with obesity [8•, 80, 81]. These discrepancies may be due to methodological differences. Specifically, studies that found lower salt sensitivity in individuals with obesity used taste strips or food stimuli; the textual properties of these stimuli may have confounded taste responses $[8 \bullet, 82,83]$. Furthermore, in studies that report higher or similar salt sensitivities in obese compared to non-obese individuals, stimulus delivery patterns may have also confounded results; whereas some studies had participants rinse the oral cavity with aqueous solutions of sodium chloride, other studies had solutions sipped or directly administered to the tongue [62, 80, 81].

To date, studies on neural responses to salty taste in obesity have been limited. In an $\left[{ }^{18}\right.$ F-Fluorodeoxyglucose (FDG)]-PET study to measure brain glucose metabolism (marker of brain function), patients with obesity showed greater OFC, insular, and parahippocampal metabolism in response to a salty taste stimulus compared to healthy controls [8•]. Increased activity in these regions was associated with reduced salt sensitivity, higher salt preference, and greater salt intake in patients with obesity [8•]. Although no perceptual differences were reported, an EEG study revealed that obese compared to non-obese individuals showed weaker and shorter-latency gustatory-evoked potentials in response to salty taste [84]. Thus, salt consumption in obesity may be associated with alterations in reward, gustatory, and memory-related areas.

\section{Umami Taste}

Umami contributes to a sense of satiety [85]. Due to its role in signaling satiety, umami has been examined in the context of weight-loss interventions and obesity [86]. Umami is a savory flavor transmitted by monosodium L-glutamate (MSG), and is recognized as one of five basic tastes largely through glutamate-binding $\mathrm{G}$ protein-coupled receptors and amino acid and nucleoside sensing receptors in taste buds [87-89]. 
Umami receptors are also expressed in the gut such that glutamate consumption is related via a vague-nerve mediated signaling pathway to the forebrain, where feeding behaviors are regulated [86, 90-94].

Studies show that umami contributes to satiety, as consumption of MSG-added (MSG+) broth increased subjective satiety in healthy-weight women compared to MSG-absent (MSG-) broth [95]. Whether this affects subsequent caloric intake is mixed. Across women with and without obesity, MSG+ soup was associated with lower calorie consumption at mealtime relative to MSG- soup [96, 97]. Women with high eating disinhibition, as assessed by the Three Factor Eating Questionnaire, consumed less saturated fat in a buffet meal following consumption of $\mathrm{MSG}+$ relative to MSG- broth [86]. However, some studies report no effect of MSG on subsequent calorie intake $[86,95]$. Together, these findings suggest that MSG influences satiety and possibly calorie consumption, especially in individuals with obesity or individuals at risk of weight gain $[86,96]$.

Some studies suggest that individuals with obesity have reduced sensitivity but higher preference for umami taste compared to individuals without obesity. Women and adolescents with obesity required higher MSG concentrations for umami taste detection compared to healthy controls [83, 98]. However, another study found that umami taste detection did not vary by BMI [22]. Interestingly, Van Langeveld et al. [99] found that individuals with obesity obtain a larger percentage of daily calories from "salt, umami, and fat"-tasting foods and less from "sweet and fat"-tasting foods than individuals without obesity reflecting perhaps a higher preference for umamitasting foods in obesity.

fMRI studies in healthy volunteers have demonstrated the effects of umami taste on brain activation patterns. Umami and glucose taste stimuli result in similar BOLD activation patterns, including the insular/opercular cortex and the caudolateral OFC, but umami resulted in greater BOLD activation in the rostral anterior cingulate cortex (ACC), a region involved in complex cognition and behavioral adjustment [100]. Increasing MSG concentration with an umami-enhancer, disodium 5'-inosinate, was associated with middle insula BOLD activation [101]. Other studies found both MSG and $\mathrm{NaCl}$ administration were associated with activation in the insula, operculum, pre- and postcentral gyrus, thalamus, supplementary motor area, and OFC [22, 102]. Moreover, umami and salty tastes were associated with stronger activation in the primary gustatory cortex in umami high-tasters compared to low-tasters [22]. Together, these findings suggest that umami and salty taste perception share a common processing system, and may thus have similar contributions to behaviors implicated in obesity.

As demonstrated with fMRI, relay of umami-related taste information to cortical areas involved in inhibitory control can further mediate subsequent food intake. In subjects with high eating disinhibition, consumption of $\mathrm{MSG}+$ relative to MSG- broth resulted in increased BOLD response in the left DLPFC, but decreased BOLD responses in regions (cerebellum, precuneus, and fusiform gyrus) that have been associated with increased motivation and attention to food; these responses were associated with lower saturated fat intake in a subsequent buffet meal [86]. Additionally, cognitive functions influence umami taste perception and its representation in the brain. MSG exposure was associated with greater insula BOLD response when participants were instructed to remember and rate the intensity relative to the pleasantness of taste, but greater medial OFC and pregenual cingulate BOLD response when participants remembered and rated the pleasantness relative to the intensity of taste; thus, selective attention, may influence umami taste perception and its valuation in the brain [103].

\section{Bitter Taste}

Bitter taste detection ability has been shown to influence dietary fat consumption, suggesting its potential relevance in obesity [104]. Bitter tastes are transduced by specialized G protein-coupled bitter taste receptors (T2Rs) [105-107]. From an evolutionary perspective, bitter tastes signal the presence of toxic food ingredients [70].

Bitter tastes affect various brain regions associated with appetite reduction. $\left[\mathrm{H}_{2}{ }^{15} \mathrm{O}\right]-\mathrm{PET}$, fMRI, and functional nearinfrared spectroscopy studies have demonstrated that bitter tastes are associated with stronger recruitment of amygdala, OFC, DLPFC, frontal operculum, and bilateral ventrolateral PFC compared to tasteless solutions in healthy volunteers [108-110]. Likewise, DLPFC responses to bitter taste stimuli are associated with appetite reduction [108]. EEG studies have further shown that bitter relative to neutral tastes also reduce appetitive ratings to high-caloric food images and are reflected in blunted event-related potentials, including fronto-central late positive potentials $[111,112]$.

Conditioning to bitter tastes also modulates hedonic evaluation. For instance, the quantity of coffee intake per week was positively associated with right caudate BOLD response to caffeine, suggesting that habitual consumption of bittertasting substances recruits reward-related areas [113]. Interestingly, lower left ACC, right precuneus, and left superior frontal gyrus BOLD responses to caffeine in caffeine consumers compared to non-caffeine consumers were associated with lower ratings of bitter taste intensity [114]. These findings may be attributed to caffeine-induced modulation of adenosine receptor density in the caudate rather than the bitter taste [115]. Furthermore, presentation of a visual cue conditioned to be mildly aversive was associated with lower insula and operculum BOLD responses and predicted lower aversion ratings to a highly aversive, bitter-tasting quinine solution [116]. Thus, altering expectations can affect subsequent taste 
perception. Further, variations in bitter taste receptor genes may also affect bitter taste perception [117].

Studies in individuals with obesity show that brain activation patterns associated with bitter tastes may influence bitter taste hedonics. For example, individuals with obesity showed stronger ACC, insula and operculum, OFC, amygdala, putamen, and pallidum activation in response to quininehydrochloride compared to individuals without obesity [118]. Activation in these areas, which modulate reward, executive function, and gustatory processing, negatively correlated with hedonic scores, suggesting that quininehydrochloride downregulates hedonic responses to bitter tastes more so in individuals with obesity [118]. Compared to healthy controls, individuals with abdominal obesity also showed greater activation in sensory and higher-level taste processing regions while evaluating bitter taste hedonics; however, no differences in hedonic ratings were reported [119•]. Mixed findings on the interaction between brain responses and hedonic ratings to bitter tastes highlight the need for more consistent and reliable measures of taste preferences in human studies $[120,121]$.

\section{Sour Taste}

Although less explored in the context of obesity, sour taste may play a role in food selection and consumption. Sour tastes are mostly registered by the polycystic-kidney disease-like ion channel, a proton channel that is sensitive to low-pH stimuli [122]. Stimulation of TRCs that contain this channel may mediate aversion to highly acidic concentrations to prevent further sour food ingestion [123, 124].

In healthy populations, fMRI studies show that sour taste stimuli, such as citric acid, recruit brain regions in an age-, sex-, and condition-dependent manner [125, 126]. For example, citric acid exposure was associated with increased caudate activation across all sated participants and in hungry females, but not in hungry males [125]. Further, neural responses to sour tastes differed by age, whereas hedonic ratings for sour tastes were independent of sex or condition [125]. Similarly, citric acid was associated with greater posterior insula BOLD response relative to water in younger compared to older adults [126].

While the neural correlates of sour taste in obesity are limited, psychophysical measures have provided insight. Adolescents with and without obesity displayed similar sensitivities to and recognition for citric acid [80, 83]. In contrast, adults with a BMI over 28 had significantly worse sour taste detection ability compared to adults with a BMI under 28 [62]. Given that sour tastes are programmed to signal toxic substances, these findings indicate the presence of long-term effects of obesity on sour taste processing and associated health outcomes [127].

\section{Clinical Implications and Research Opportunities}

While chemosensory stimuli interact with TRCs in the tongue to generate taste perception in the brain, taste also results from the interaction of chemosensory stimuli with extraoral TRCs, including those in the gastrointestinal (GI) tract [128-130]. Although their function continues to be explored, GI taste receptors (i.e., sweet, bitter, fat, and amino acid receptors) appear to modulate satiety hormones [131-135]. Furthermore, dysregulation of chemosensory pathways in the gut may contribute to increased risk for obesity [136]. Given the importance of taste perception in neuroendocrine functions, TRCs in the GI tract could offer potential therapeutic targets in obesity [137••].

Intragastric administration of quinine and/or MSG can alter brain activation patterns in regions (insula, subcortical limbic and memory structures, homeostatic and hedonic centers) that regulate food intake $[129,130]$. Further, intragastric administration of quinine can lead to lower hunger scores and hedonic eating, which were associated with changes in orexigenic and satiety gut hormone levels $[128,138,139]$. That gut taste receptor stimulation affects brain activation patterns underscores the importance of oral-nasal-brain-gut axis signaling in chemosensory pathways associated with appetite regulation, which may elucidate how nutritional interventions target these pathways in obesity.

Studies of bariatric surgery on taste activation patterns in obese populations lend further support for gut-brain axis signaling in postoral nutrient sensing, or appetition. Indeed, bariatric surgery has been shown to recover structural abnormalities and mu-opioid receptor density in the insula [140, 141]. Additionally, following bariatric surgery, the insula showed decreased restingstate activity compared to pre-bariatric surgery, which may reflect reduced interoceptive attention to hunger signals $[142,143]$.

While these studies show that vagal and gut-brain hormonal signaling promotes satiety to control food intake in a negativefeedback manner, appetition, a distinct process from satiation, can drive positive reinforcement of food intake [144••]. Conditioning studies in rodents have demonstrated that flavored solutions paired with intragastric infusion of palatable foods modulate flavor preferences, suggesting that gut-brain signaling mechanisms drive appetition and increased food intake via postoral nutrient-conditioned preferences [145-147]. More research on these mechanisms may help identify better targets for pharmacological blockade and subsequent reversal of nutrient-conditioned flavor preferences [144••].

Collectively, more research addressing the clinical implications of taste perception and extraoral chemosensory receptors in obesity are needed to understand how different interventions such as exercise may affect taste perception. For example, exercise has recently been associated with increased sensitivity and lower hedonic ratings to sweet and umami tastes [148••]. In adolescents with obesity, high intensity interval 
exercise was associated with lower fat and sweet taste preferences and lower fat implicit wanting, all of which contributed to reduced food intake [149]. With neuroimaging, the effects of exercise on taste and smell perception would help elucidate the neurobiological basis of exercise in the prevention of obesity. Such knowledge could potentially help clinicians use activity levels to guide personalized nutritional and dietary interventions for obesity in the future.

\section{Summary and Conclusion}

In this review, we summarize the neural correlates of umami, salty, fat, bitter, and sour tastes that may be altered in obesity, as outlined in Table 1. While sweet taste is widely linked to obesity, additional primary tastes, particularly fat and umami, may also be implicated. Alterations in the neural correlates of the basic tastes, notably fat and umami, may reflect different hedonic responses to taste information in obesity. However, limited and conflicting findings of neuroimaging outcomes on bitter, salty, and sour tastes highlight their inconclusive role in obesity.

Fat tastes recruit reward, executive control, and gustatory brain regions that regulate dietary restraint [48-51]. Reduced neural responses to fat in these regions have been associated with increased intake of highly palatable food. Several fMRI studies have supported these findings, demonstrating differential BOLD responses to fat taste in participants who were obese or overweight compared to healthy controls, particularly in the gustatory cortex and reward pathway $[9,10]$. Thus, hedonic eating in obesity may be driven by individual differences in the neural mechanisms of fat taste perception. Further, variations in the $C D 36$ taste receptor gene have been associated with obesity in humans [13].

Similar to fat, umami tastes recruit reward, executive control, gustatory, and salience networks in the brain, and are associated with satiety levels. MSG has been studied for its role in appetite suppression and calorie restriction [96, 97]. Further, fMRI studies suggest that MSG influences BOLD activation patterns in areas related to dietary restriction and attention to food [86]. Together, these findings highlight the relevance of umami in obesity in the context of weight loss. Studies of both fat and umami found links between taste stimuli-induced BOLD response and impulsivity, which further implicates taste perception in disinhibited eating and obesity $[10,86]$.

Although not discussed in this review, sweet tastes are associated with altered activation in reward, executive control, homeostatic, and affective brain regions in individuals with obesity. Obese compared to healthy-weight individuals show decreased perfusion in the PFC but increased perfusion in the hypothalamus following glucose and fructose consumption [150]. In addition, obese and overweight compared to healthy-weight individuals show differential BOLD response to sweet taste in reward, gustatory, and affective brain regions; however, whether sweet taste coincided with differences in hedonic and behavioral measures was mixed $[9,10,119 \bullet, 151]$.

Together, these findings illustrate the neurobiological underpinnings of taste modalities and hedonics to food tastes and their relevance in obesity. While neuroimaging studies of fat and umami tastes show the most robust association with obesity in the present review, further studies on brain activation responses to sour, salty, and bitter tastes are needed to understand the interplay of primary taste perception in cognitive control over eating behaviors and dietary restraint. Given that smell modulates taste perception to influence food intake, more neuroimaging studies of smell in obesity are also needed. Indeed, application of odorant stimuli delivery techniques to neuroimaging procedures such as fMRI and EEG has started to gain traction in recent years [152, 153]. Further neuroimaging research is also needed to better characterize the influence that taste receptors in the gut have on brain responses following food consumption. A greater understanding of the brain responses to taste and smell in obesity may help inform prevention and treatment efforts.

Funding Information The project was supported by NIH Intramural Research Program of the National Institute on Alcoholism and Alcohol Abuse, Y01AA3009 (CKL, DEF, DSK, JAB, PM, NDV, GJW) and National Institute of Nursing Research under award number, ZIANR000035-01 (PVJ). PVJ is also supported by the Office of Workforce Diversity, National Institutes of Health Distinguished Scholar and the Rockefeller University Heilbrunn Nurse Scholar Award.

\section{Compliance with Ethical Standards}

Conflict of Interest Christopher Kure Liu, Paule Valery Joseph, Dana E. Feldman, Danielle S. Kroll, Jamie A. Burns, Peter Manza, Nora D. Volkow, and Gene-Jack Wang declare they have no conflict of interest.

Human and Animal Rights and Informed Consent This article does not contain any studies with human or animal subjects performed by any of the authors.

Open Access This article is distributed under the terms of the Creative Commons Attribution 4.0 International License (http:// creativecommons.org/licenses/by/4.0/), which permits unrestricted use, distribution, and reproduction in any medium, provided you give appropriate credit to the original author(s) and the source, provide a link to the Creative Commons license, and indicate if changes were made.

\section{References}

Papers of particular interest, published recently, have been highlighted as:

- Of importance

•. Of major importance

1. Ogden CL, Carroll MD, Lawman HG, Fryar CD, Kruszon-Moran $\mathrm{D}, \mathrm{Kit} \mathrm{BK}$, et al. Trends in obesity prevalence among children and adolescents in the United States, 1988-1994 through 2013-2014. JAMA. 2016;315(21):2292-9. https://doi.org/10.1001/jama. 2016.6361 . 
2.• Hales CM, Carroll MD, Fryar CD, Ogden CL. Prevalence of obesity among adults and youth: United States, 2015-2016. NCHS Data Brief. 2017;288:1-8 The prevalence of obesity has been increasing in the United States. More research on the underlying causes of obesity will bring greater public attention to this epidemic.

3. Chinese Diabetes Society. Chinese guidelines for the prevention and treatment of type 2 diabetes. Chin J Diabetes Mellitus. 2014;6: 447-96.

4. Guidelines. For managing overweight and obesity in adults. Preface to the expert panel report (comprehensive version which includes systematic evidence review, evidence statements, and recommendations). Obesity (Silver Spring). 2013;22(Suppl 2): S40. https://doi.org/10.1002/oby.20822.

5. Amine EK, Baba NH, Belhadj M, Deurenberg-Yap M, Djazayery A, Forrestre T, et al. Diet, nutrition and the prevention of chronic diseases. World Health Organ Tech Rep Ser. 2003;916:i-viii, 1149 backcover

6. Martínez Steele E, Popkin BM, Swinburn B, Monteiro CA. The share of ultra-processed foods and the overall nutritional quality of diets in the US: evidence from a nationally representative crosssectional study. Popul Health Metrics. 2017;15(1):6. https://doi. org/10.1186/s12963-017-0119-3.

7. Martínez Steele E, Baraldi LG, Louzada MLC, Moubarac J-C, Mozaffarian D, Monteiro CA. Ultra-processed foods and added sugars in the US diet: evidence from a nationally representative cross-sectional study. BMJ Open. 2016;6(3):e009892. https://doi. org/10.1136/bmjopen-2015-009892.

8. Li Q, Jin R, Yu H, Lang H, Cui Y, Xiong S, et al. Enhancement of neural salty preference in obesity. Cell Physiol Biochem. 2017;43(5):1987-2000. https://doi.org/10.1159/000484122 With lower salt sensitivity and higher salty preference, individuals who are overweight or have obesity are prone to consume more salt. Brain imaging reveals unique neural mechanisms associated with altered salty taste perception in overweight and obese populations. Findings from this study suggest that modifying neural processing of salty taste perception can reduce daily salt intake in overweight or obese populations.

9. Bohon C. Brain response to taste in overweight children: a pilot feasibility study. PLoS One. 2017;12(2):e0172604. https://doi. org/10.1371/journal.pone.0172604.

10. Babbs RK, Sun X, Felsted J, Chouinard-Decorte F, Veldhuizen MG, Small DM. Decreased caudate response to milkshake is associated with higher body mass index and greater impulsivity. Physiol Behav. 2013;121:103-11. https://doi.org/10.1016/j. physbeh.2013.03.025.

11. de Araujo IE, Oliveira-Maia AJ, Sotnikova TD, Gainetdinov RR, Caron MG, Nicolelis MA, et al. Food reward in the absence of taste receptor signaling. Neuron. 2008;57(6):930-41. https://doi. org/10.1016/j.neuron.2008.01.032.

12. Prinster A, Cantone E, Verlezza V, Magliulo M, Sarnelli G, Iengo $\mathrm{M}$, et al. Cortical representation of different taste modalities on the gustatory cortex: a pilot study. PLoS One. 2017;12(12):e0190164. https://doi.org/10.1371/journal.pone.0190164.

13. Liu D, Archer N, Duesing K, Hannan G, Keast R. Mechanism of fat taste perception: association with diet and obesity. Prog Lipid Res. 2016;63:41-9. https://doi.org/10.1016/j.plipres.2016.03.002.

14. Mattes RD. Accumulating evidence supports a taste component for free fatty acids in humans. Physiol Behav. 2011;104(4):624 31. https://doi.org/10.1016/j.physbeh.2011.05.002.

15. Keast RS, Costanzo A. Is fat the sixth taste primary? Evidence and implications. Flavour. 2015;4(1):5. https://doi.org/10.1186/20447248-4-5.

16. Reed DR, Xia MB. Recent advances in fatty acid perception and genetics. Adv Nutr. 2015;6(3):353S-60S. https://doi.org/10.3945/ an.114.007005.
17. Yamamoto T. Central mechanisms of taste: cognition, emotion and taste-elicited behaviors. Jpn Dent Sci Rev. 2008;44(2):91-9. https://doi.org/10.1016/j.dsr.2008.07.003.

18. Yamamoto T. Neural substrates for the processing of cognitive and affective aspects of taste in the brain. Arch Histol Cytol. 2006;69(4):243-55. https://doi.org/10.1679/aohc.69.243.

19. Monteleone P, Piscitelli F, Scognamiglio P, Monteleone AM, Canestrelli B, Di Marzo V, et al. Hedonic eating is associated with increased peripheral levels of ghrelin and the endocannabinoid 2arachidonoyl-glycerol in healthy humans: a pilot study. J Clin Endocrinol Metab. 2012;97(6):E917-E24. https://doi.org/10. 1210/jc.2011-3018.

20. Sclafani A, Ackroff K. Glucose- and fructose-conditioned flavor preferences in rats: taste versus postingestive conditioning. Physiol Behav. 1994;56(2):399-405. https://doi.org/10.1016/ 0031-9384(94)90213-5.

21. Jiang T, Soussignan R, Schaal B, Royet JP. Reward for food odors: an fMRI study of liking and wanting as a function of metabolic state and BMI. Soc Cogn Affect Neurosci. 2015;10(4):561-8. https://doi.org/10.1093/scan/nsu086.

22. Han JE, Frasnelli J, Zeighami Y, Larcher K, Boyle J, McConnell $\mathrm{T}$, et al. Food odor conditioning in healthy humans: an fMRI study. Cell Rep. 2018;25(10):2643-2652.e4. https://doi.org/10.1016/j. celrep.2018.11.026.

23. Sorokowska A, Schoen K, Hummel C, Han P, Warr J, Hummel T. Food-related odors activate dopaminergic brain areas. Front Hum Neurosci. 2017;11:625. https://doi.org/10.3389/fnhum.2017. 00625 .

24. Riera CE, Tsaousidou E, Halloran J, Follett P, Hahn O, Pereira MMA, et al. The sense of smell impacts metabolic health and obesity. Cell Metab. 2017;26(1):198-211.e5. https://doi.org/10. 1016/j.cmet.2017.06.015.

25. Lindgren E, Gray K, Miller G, Tyler R, Wiers CE, Volkow ND, et al. Food addiction: a common neurobiological mechanism with drug abuse. Front Biosci (Landmark Ed). 2018;23:811-36. Review. https://doi.org/10.2741/4618.

26. Tomasi D, Volkow ND. Striatocortical pathway dysfunction in addiction and obesity: differences and similarities. Crit Rev Biochem Mol Biol. 2013;48(1):1-19. https://doi.org/10.3109/ 10409238.2012.735642.

27. Volkow ND, Wise RA, Baler R. The dopamine motive system: implications for drug and food addiction. Nat Rev Neurosci. 2017;18(12):741-52. https://doi.org/10.1038/nrn.2017.130.

28. Lee PC, Dixon JB. Food for thought: reward mechanisms and hedonic overeating in obesity. Curr Obes Rep. 2017;6(4):35361. https://doi.org/10.1007/s13679-017-0280-9.

29. Wang G-J, Volkow ND, Felder C, Fowler JS, Levy AV, Pappas NR, et al. Enhanced resting activity of the oral somatosensory cortex in obese subjects. NeuroReport. 2002;13(9):1151-5. https://doi.org/10.1097/00001756-200207020-00016.

30. Wang G-J, Volkow ND, Thanos PK, Fowler JS. Similarity between obesity and drug addiction as assessed by neurofunctional imaging. J Addict Dis. 2004;23(3):39-53. https://doi.org/10.1300/ J069v23n03 04.

31. Volkow ND, Wang GJ, Telang F, Fowler JS, Thanos PK, Logan J, et al. Low dopamine striatal D2 receptors are associated with prefrontal metabolism in obese subjects: possible contributing factors. Neuroimage. 2008;42(4):1537-43. https://doi.org/10.1016/j. neuroimage.2008.06.002.

32. Volkow ND, Wang G-J, Telang F, Fowler JS, Goldstein RZ, AliaKlein N, et al. Inverse association between BMI and prefrontal metabolic activity in healthy adults. Obesity. 2009;17(1):60-5. https://doi.org/10.1038/oby.2008.469.

33. Patriarca L, Magerowski G, Alonso-Alonso M. Functional neuroimaging in obesity. Curr Opin Endocrinol. 2017;24(3):260-5. https://doi.org/10.1097/MED.0000000000000340. 
34. B-y P, Lee MJ, Kim M, Kim S-H, Park H. Structural and functional brain connectivity changes between people with abdominal and non-abdominal obesity and their association with behaviors of eating disorders. Front Neurosci-Switz. 2018;12:741. https://doi. org/10.3389/fnins.2018.00741.

35. Schlögl H, Horstmann A, Villringer A, Stumvoll M. Functional neuroimaging in obesity and the potential for development of novel treatments. Lancet Diabetes Endocrinol. 2016;4(8):695705. https://doi.org/10.1016/S2213-8587(15)00475-1.

36. Zhang B, Tian D, Yu C, Zhang J, Tian X, von Deneen KM, et al. Altered baseline brain activities before food intake in obese men: a resting state fMRI study. Neurosci Lett. 2015;584:156-61. https:// doi.org/10.1016/j.neulet.2014.10.020.

37. Iwata S, Yoshida R, Ninomiya Y. Taste transductions in taste receptor cells: basic tastes and moreover. Curr Pharm Des. 2014;20(16):2684-92. https://doi.org/10.2174/ 13816128113199990575.

38. Freeman CR, Zehra A, Ramirez V, Wiers CE, Volkow ND, Wang GJ. Impact of sugar on the body, brain, and behavior. Front Biosci (Landmark Ed). 2018;23:2255-66. https://doi.org/10.2741/4704.

39. Pastor A, Fernández-Aranda F, Fitó M, Jiménez-Murcia S, Botella C, Fernández-Real JM, et al. A lower olfactory capacity is related to higher circulating concentrations of endocannabinoid 2arachidonoylglycerol and higher body mass index in women. PLoS One. 2016;11(2):e0148734. https://doi.org/10.1371/ journal.pone.0148734.

40. Peng M, Coutts D, Wang T, Cakmak YO. Systematic review of olfactory shifts related to obesity. Obes Rev. 2019;20(2):325-38. https://doi.org/10.1111/obr.12800.

41. Bragulat V, Dzemidzic M, Bruno C, Cox CA, Talavage T, Considine RV, et al. Food-related odor probes of brain reward circuits during hunger: a pilot FMRI study. Obesity (Silver Spring). 2010;18(8):1566-71. https://doi.org/10.1038/oby.2010. 57.

42. Eiler WJ 2nd, Dzemidzic M, Case KR, Considine RV, Kareken DA. Correlation between ventromedial prefrontal cortex activation to food aromas and Cue-driven eating: an fMRI study. Chemosens Percept. 2012;5(1):27-36. https://doi.org/10.1007/ s12078-011-9112-6.

43. Eiler WJ 2nd, Dzemidzic M, Case KR, Armstrong CL, Mattes $\mathrm{RD}$, Cyders MA, et al. Ventral frontal satiation-mediated responses to food aromas in obese and normal-weight women. Am J Clin Nutr. 2014;99(6):1309-18. https://doi.org/10.3945/ ajcn.113.080788

44. Sinclair EB, Culbert KM, Gradl DR, Richardson KA, Klump KL, Sisk CL. Differential mesocorticolimbic responses to palatable food in binge eating prone and binge eating resistant female rats. Physiol Behav. 2015;152(Pt A):249-56. https://doi.org/10.1016/j. physbeh.2015.10.012.

45. Hill JO, Melanson EL, Wyatt HT. Dietary fat intake and regulation of energy balance: implications for obesity. J Nutr. 2000;130(2S Suppl):284S-8S. https://doi.org/10.1093/jn/130.2.284S.

46. Abumrad NA. CD36 may determine our desire for dietary fats. J Clin Invest. 2005;115(11):2965-7. https://doi.org/10.1172/ JCI26955.

47. Sclafani A, Ackroff K, Abumrad N. Fat preference and acceptance in the CD36 knockout mice. Appetite. 2007;49(1):329. https://doi. org/10.1016/j.appet.2007.03.184.

48. Grabenhorst F, Rolls ET, Parris BA, d'Souza AA. How the brain represents the reward value of fat in the mouth. Cereb Cortex. 2010;20(5):1082-91. https://doi.org/10.1093/cercor/bhp169.

49. de Araujo IE, Rolls ET. Representation in the human brain of food texture and oral fat. J Neurosci. 2004;24(12):3086-93. https://doi. org/10.1523/j.neuroscience.0130-04.2004.

50. Tzieropoulos H, Rytz A, Hudry J, le Coutre J. Dietary fat induces sustained reward response in the human brain without primary taste cortex discrimination. Front Hum Neurosci. 2013;7:36. https://doi.org/10.3389/fnhum.2013.00036.

51. Stice E, Burger KS, Yokum S. Relative ability of fat and sugar tastes to activate reward, gustatory, and somatosensory regions. Am J Clin Nutr. 2013;98(6):1377-84. https://doi.org/10.3945/ ajen.113.069443.

52. Barry RL, Byun NE, Williams JM, Siuta MA, Tantawy MN, Speed NK, et al. Brief exposure to obesogenic diet disrupts brain dopamine networks. PLoS One. 2018;13(4):e0191299. https:// doi.org/10.1371/journal.pone.0191299.

53. Alsiö J, Olszewski PK, Norbäck AH, Gunnarsson ZEA, Levine AS, Pickering C, et al. Dopamine D1 receptor gene expression decreases in the nucleus accumbens upon long-term exposure to palatable food and differs depending on diet-induced obesity phenotype in rats. Neuroscience. 2010;171(3):779-87. https://doi.org/ 10.1016/j.neuroscience.2010.09.046.

54. Eldeghaidy S, Marciani L, Hort J, Hollowood T, Singh G, Bush D, et al. Prior consumption of a fat meal in healthy adults modulates the brain's response to fat. J Nutr. 2016;146(11):2187-98. https:// doi.org/10.3945/jn.116.234104.

55. Stice E, Yokum S. Relation of neural response to palatable food tastes and images to future weight gain: using bootstrap sampling to examine replicability of neuroimaging findings. NeuroImage. 2018;183:522-31. https://doi.org/10.1016/j.neuroimage.2018.08. 035.

56. Rocchini AP, Key J, Bondie D, Chico R, Moorehead C, Katch V, et al. The effect of weight loss on the sensitivity of blood pressure to sodium in obese adolescents. N Engl J Med. 1989;321(9):580 5. https://doi.org/10.1056/NEJM198908313210905.

57. Ma Y, He FJ, MacGregor GA. High salt intake: independent risk factor for obesity? Hypertension. 2015;66(4):843-9. https://doi. org/10.1161/HYPERTENSIONAHA.115.05948.

58. Bobowski NK, Mennella JA. Disruption in the relationship between blood pressure and salty taste thresholds among overweight and obese children. J Acad Nutr Diet. 2015;115(8):1272-82. https://doi.org/10.1016/j.jand.2015.02.017.

59. Yoon YS, Oh SW. Sodium density and obesity; the Korea National Health and Nutrition Examination Survey 2007-2010. Eur J Clin Nutr. 2012;67:141-6. https://doi.org/10.1038/ejen. 2012.204.

60. Yi SS, Kansagra SM. Associations of sodium intake with obesity, body mass index, waist circumference, and weight. Am J Prev Med. 2014;46(6):e53-e5. https://doi.org/10.1016/j.amepre.2014. 02.005 .

61. Bertoli S, Laureati M, Battezzati A, Bergamaschi V, Cereda E, Spadafranca A, et al. Taste sensitivity, nutritional status and metabolic syndrome: implication in weight loss dietary interventions. World J Diabetes. 2014;5(5):717-23. https://doi.org/10.4239/wjd. v5.i5.717.

62. Simchen U, Koebnick C, Hoyer S, Issanchou S, Zunft HJ. Odour and taste sensitivity is associated with body weight and extent of misreporting of body weight. Eur J Clin Nutr. 2006;60:698-705. https://doi.org/10.1038/sj.ejcn.1602371.

63. Stähler F, Riedel K, Demgensky S, Neumann K, Dunkel A, Täubert A, et al. A role of the epithelial sodium channel in human salt taste transduction? Chem Perception. 2008;1:78-90. https:// doi.org/10.1007/s12078-008-9006-4.

64. Yoshida R, Horio N, Murata Y, Yasumatsu K, Shigemura N, Ninomiya $\mathrm{Y} . \mathrm{NaCl}$ responsive taste cells in the mouse fungiform taste buds. Neuroscience. 2009;159(2):795-803. https://doi.org/ 10.1016/j.neuroscience.2008.12.052.

65. Lyall V, Heck GL, Vinnikova AK, Ghosh S, Phan TH, Alam RI, et al. The mammalian amiloride-insensitive non-specific salt taste receptor is a vanilloid receptor-1 variant. J Physiol. 2004;558(Pt 1):147-59. https://doi.org/10.1113/jphysiol.2004.065656. 
66. Chandrashekar J, Kuhn C, Oka Y, Yarmolinsky DA, Hummler E, Ryba NJ, et al. The cells and peripheral representation of sodium taste in mice. Nature. 2010;464(7286):297-301. https://doi.org/ 10.1038 /nature 08783 .

67. Ruiz C, Gutknecht S, Delay E, Kinnamon S. Detection of $\mathrm{NaCl}$ and $\mathrm{KCl}$ in TRPV1 knockout mice. Chem Senses. 2006;31(9): 813-20. https://doi.org/10.1093/chemse/bj1024.

68. Oka Y, Butnaru M, von Buchholtz L, Ryba NJP, Zuker CS. High salt recruits aversive taste pathways. Nature. 2013;494:472-5. https://doi.org/10.1038/nature11905.

69. Yeung AWK, Tanabe HC, Suen JLK, Goto TK. Taste intensity modulates effective connectivity from the insular cortex to the thalamus in humans. NeuroImage. 2016;135:214-22. https://doi. org/10.1016/j.neuroimage.2016.04.057.

70. Lindemann B. Taste reception. Physiol Rev. 1996;76(3):719-66. https://doi.org/10.1152/physrev.1996.76.3.719.

71. Beauchamp GK, Bertino M, Burke D, Engelman K. Experimental sodium depletion and salt taste in normal human volunteers. Am J Clin Nutr. 1990;51(5):881-9. https://doi.org/10.1093/ajcn/51.5. 881.

72. Mun CW, Kim SH, Choi KS, Lee HY, Shin WJ, Eun CK. Saltytaste activation of human brain disclosed by gustatory fMRI study. J Korean Soc Magn Reson Med. 2005;9(1):30-5. https://doi.org/ 10.13104/jksmrm.2005.9.1.30

73. Han P, Mohebbi M, Unrath M, Hummel C, Hummel T. Different neural processing of umami and salty taste determined by umami identification ability independent of repeated umami exposure. Neuroscience. 2018;383:74-83. https://doi.org/10.1016/j. neuroscience.2018.05.004.

74. Hollmann M, Hellrung L, Pleger B, Schlögl H, Kabisch S, Stumvoll M, et al. Neural correlates of the volitional regulation of the desire for food. Int J Obes. 2011;36:648-55. https://doi.org/ 10.1038/ijo.2011.125.

75. Scharmüller W, Übel S, Ebner F, Schienle A. Appetite regulation during food cue exposure: a comparison of normal-weight and obese women. Neurosci Lett. 2012;518(2):106-10. https://doi. org/10.1016/j.neulet.2012.04.063.

76. Hare TA, Camerer CF, Rangel A. Self-control in decision-making involves modulation of the vmPFC valuation system. Science. 2009;324(5927):646-8. https://doi.org/10.1126/science.1168450.

77. Weygandt M, Mai K, Dommes E, Leupelt V, Hackmack K, Kahnt $\mathrm{T}$, et al. The role of neural impulse control mechanisms for dietary success in obesity. NeuroImage. 2013;83:669-78. https://doi.org/ 10.1016/j.neuroimage.2013.07.028.

78. Zald DH, Lee JT, Fluegel KW, Pardo JV. Aversive gustatory stimulation activates limbic circuits in humans. Brain. 1998;121(Pt 6): 1143-54. https://doi.org/10.1093/brain/121.6.1143.

79. Spetter MS, Smeets PAM, de Graaf C, Viergever MA. Representation of sweet and salty taste intensity in the brain. Chem Senses. 2010;35(9):831-40. https://doi.org/10.1093/ chemse/bjq093.

80. Pasquet P, Laure Frelut M, Simmen B, Marcel Hladik C, Monneuse M-O. Taste perception in massively obese and in non-obese adolescents. Int J Pediatr Obes. 2007;2(4):242-8. https://doi.org/10.1080/17477160701440521.

81. Hardikar S, Höchenberger R, Villringer A, Ohla K. Higher sensitivity to sweet and salty taste in obese compared to lean individuals. Appetite. 2017;111:158-65. https://doi.org/10.1016/j.appet. 2016.12.017.

82. Skrandies W, Zschieschang R. Olfactory and gustatory functions and its relation to body weight. Physiol Behav. 2015;142:1-4. https://doi.org/10.1016/j.physbeh.2015.01.024.

83. Overberg J, Hummel T, Krude H, Wiegand S. Differences in taste sensitivity between obese and non-obese children and adolescents. Arch Dis Child. 2012;97(12):1048-52. https://doi.org/10.1136/ archdischild-2011-301189.
84. Hardikar S, Wallroth R, Villringer A, Ohla K. Shorter-lived neural taste representations in obese compared to lean individuals. Sci Rep. 2018;8(1):11027. https://doi.org/10.1038/s41598-01828847-3.

85. Masic U, Yeomans MR. Umami flavor enhances appetite but also increases satiety. Am J Clin Nutr. 2014;100(2):532-8. https://doi. org/10.3945/ajen.113.080929.

86. Magerowski G, Giacona G, Patriarca L, Papadopoulos K, GarzaNaveda P, Radziejowska J, et al. Neurocognitive effects of umami: association with eating behavior and food choice. Neuropsychopharmacol. 2018;43(10):2009-16. https://doi.org/ 10.1038/s41386-018-0044-6.

87. Torii K, Mimura T, Yugari Y. Biochemical mechanism of umami taste perception and effect of dietary protein on the taste preference for amino acids and sodium chloride in rats. In: Kawamura Y, Kare MR, editors. Umami: a basic taste. New York: Marcel Dekker Inc; 1987.

88. Chaudhari N, Landin AM, Roper SD. A metabotropic glutamate receptor variant functions as a taste receptor. Nat Neurosci. 2000;3(2):113-9. https://doi.org/10.1038/72053.

89. Chaudhari N, Pereira E, Roper SD. Taste receptors for umami: the case for multiple receptors. Am J Clin Nutr. 2009;90(3):738S42S. https://doi.org/10.3945/ajen.2009.27462H.

90. Torii K, Uneyama H, Nakamura E. Physiological roles of dietary glutamate signaling via gut-brain axis due to efficient digestion and absorption. J Gastroenterol. 2013;48(4):442-51. https://doi. org/10.1007/s00535-013-0778-1.

91. Tsurugizawa T, Uematsu A, Nakamura E, Hasumura M, Hirota M, Kondoh T, et al. Mechanisms of neural response to gastrointestinal nutritive stimuli: the gut-brain axis. Gastroenterology. 2009;137: 262-73. https://doi.org/10.1053/j.gastro.2009.02.057.

92. Tsurugizawa $\mathrm{T}$, Uneyama $\mathrm{H}$, Torii $\mathrm{K}$. Brain amino acid sensing. Diabetes Obes Metab. 2014;16:41-8. https://doi.org/10.1111/ dom. 12336.

93. Uneyama H, Niijima A, San Gabriel A, Torii K. Luminal amino acid sensing in the rat gastric mucosa. Am J Physiol Gastrointest Liver Physiol. 2006;291:G1163-70. https://doi.org/10.1152/ajpgi. 00587.2005 .

94. Tomé D. The roles of dietary glutamate in the intestine. Ann Nutr Metab. 2018;73(Suppl 5):15-20. https://doi.org/10.1159/ 000494777.

95. Carter BE, Monsivais P, Perrigue MM, Drewnowski A. Supplementing chicken broth with monosodium glutamate reduces hunger and desire to snack but does not affect energy intake in women. Br J Nutr. 2011;106(9):1441-8. https://doi.org/10. 1017/S0007114511001759.

96. Miyaki T, Imada T, Hao SS, Kimura E. Monosodium L-glutamate in soup reduces subsequent energy intake from high-fat savoury food in overweight and obese women. Br J Nutr. 2016;115(1): 176-84. https://doi.org/10.1017/S0007114515004031.

97. Imada T, Hao SS, Torii K, Kimura E. Supplementing chicken broth with monosodium glutamate reduces energy intake from high fat and sweet snacks in middle-aged healthy women. Appetite. 2014;79:158-65. https://doi.org/10.1016/j.appet.2014. 04.011.

98. Pepino MY, Finkbeiner S, Beauchamp GK, Mennella JA. Obese women have lower monosodium glutamate taste sensitivity and prefer higher concentrations than do normal-weight women. Obesity. 2010;18(5):959-65. https://doi.org/10.1038/oby.2009. 493.

99. van Langeveld AWB, Teo PS, de Vries JHM, Feskens EJM, de GraafC, Mars M. Dietary taste patterns by sex and weight status in the Netherlands. Br J Nutr. 2018;119(10):1195-206. https://doi. org/10.1017/S0007114518000715.

100. de Araujo IE, Kringelbach ML, Rolls ET, Hobden P. Representation of umami taste in the human brain. J 
Neurophysiol. 2003;90(1):313-9. https://doi.org/10.1152/jn. 00669.2002.

101. Nakamura Y, Goto TK, Tokumori K, Yoshiura T, Kobayashi K, Nakamura Y, et al. Localization of brain activation by umami taste in humans. Brain Res. 2011;1406:18-29. https://doi.org/10.1016/ j.brainres.2011.06.029.

102. Iannilli E, Singh PB, Schuster B, Gerber J, Hummel T. Taste laterality studied by means of umami and salt stimuli: an fMRI study. NeuroImage. 2012;60(1):426-35. https://doi.org/10.1016/j. neuroimage.2011.12.088.

103. Grabenhorst F, Rolls ET. Selective attention to affective value alters how the brain processes taste stimuli. Eur J Neurosci. 2008;27(3):723-9. https://doi.org/10.1111/j.1460-9568.2008. 06033.x.

104. Keller KL, Adise S. Variation in the ability to taste bitter thiourea compounds: implications for food acceptance, dietary intake, and obesity risk in children. Annu Rev Nutr. 2016;36:157-82. https:// doi.org/10.1146/annurev-nutr-071715-050916.

105. Adler E, Hoon MA, Mueller KL, Chandrashekar J, Ryba NJP, Zuker CS. A novel family of mammalian taste receptors. Cell. 2000;100(6):693-702. https://doi.org/10.1016/S0092-8674(00) 80705-9.

106. Chandrashekar J, Mueller KL, Hoon MA, Adler E, Feng L, Guo W, et al. T2Rs function as bitter taste receptors. Cell. 2000;100(6): 703-11. https://doi.org/10.1016/S0092-8674(00)80706-0.

107. Matsunami H, Montmayeur J-P, Buck LB. A family of candidate taste receptors in human and mouse. Nature. 2000;404:601. https://doi.org/10.1038/35007072.

108. Wabnegger A, Schwab D, Schienle A. Aversive aftertaste changes visual food cue reactivity: an fMRI study on cross-modal perception. Neurosci Lett. 2018;673:56-60. https://doi.org/10.1016/j. neulet.2018.02.060.

109. Bembich S, Lanzara C, Clarici A, Demarini S, Tepper BJ, Gasparini P, et al. Individual differences in prefrontal cortex activity during perception of bitter taste using fNIRS methodology. Chem Senses. 2010;35(9):801-12. https://doi.org/10.1093/ chemse/bjq080.

110. Zald DH, Hagen MC, Pardo JV. Neural correlates of tasting concentrated quinine and sugar solutions. J Neurophysiol. 2002;87(2): 1068-75. https://doi.org/10.1152/jn.00358.2001.

111. Schwab D, Giraldo M, Spiegl B, Schienle A. Disgust evoked by strong wormwood bitterness influences the processing of visual food cues in women: an ERP study. Appetite. 2017;108:51-6. https://doi.org/10.1016/j.appet.2016.09.023.

112. Schienle A, Scharmüller W, Schwab D. Processing of visual food cues during bitter taste perception in female patients with bingeeating symptoms: a cross-modal ERP study. Clin Neurophysiol. 2017;128(11):2184-90. https://doi.org/10.1016/j.clinph.2017.08. 017.

113. Kishi M, Sadachi H, Nakamura J, Tonoike M. Functional magnetic resonance imaging investigation of brain regions associated with astringency. Neurosci Res. 2017;122:9-16. https://doi.org/ 10.1016/j.neures.2017.03.009.

114. Gramling L, Kapoulea E, Murphy C. Taste perception and caffeine consumption: an fMRI study. Nutrients. 2018;11(1). https://doi. org/10.3390/nu11010034.

115. Johansson B, Georgiev V, Lindström K, Fredholm BB. A1 and $\mathrm{A} 2 \mathrm{~A}$ adenosine receptors and A1 mRNA in mouse brain: effect of long-term caffeine treatment. Brain Res. 1997;762(1-2):153-64. https://doi.org/10.1016/S0006-8993(97)00378-8.

116. Nitschke JB, Dixon GE, Sarinopoulos I, Short SJ, Cohen JD, Smith EE, et al. Altering expectancy dampens neural response to aversive taste in primary taste cortex. Nat Neurosci. 2006;9(3): 435-42. https://doi.org/10.1038/nn1645.

117. Hwang LD, Gharahkhani P, Breslin PAS, Gordon SD, Zhu G, Martin NG, et al. Bivariate genome-wide association analysis strengthens the role of bitter receptor clusters on chromosomes 7 and 12 in human bitter taste. BMC Genomics. 2018;19(1):678. https://doi.org/10.1186/s12864-018-5058-2.

118. Szalay C, Aradi M, Schwarcz A, Orsi G, Perlaki G, Németh L, et al. Gustatory perception alterations in obesity: an fMRI study. Brain Res. 2012;1473:131-40. https://doi.org/10.1016/j.brainres. 2012.07.051.

119. Green E, Jacobson A, Haase L, Murphy C. Neural correlates of taste and pleasantness evaluation in the metabolic syndrome. Brain Res. 2015;1620:57-71. https://doi.org/10.1016/j.brainres. 2015.03.034 Individuals with metabolic syndrome show lower brain activation to sweet and bitter tastes in sensorylevel and reward-processing regions compared to healthy controls. Findings provide better understanding of neurobiological underpinnings of overeating that have been related to reduced reward processing.

120. Wichchukit S, O'Mahony M. The 9-point hedonic scale and hedonic ranking in food science: some reappraisals and alternatives. J Sci Food Agric. 2015;95(11):2167-78. https://doi.org/10.1002/ jsfa.6993.

121. Kalva JJ, Sims CA, Puentes LA, Snyder DJ, Bartoshuk LM. Comparison of the hedonic general labeled magnitude scale with the hedonic 9-point scale. J Food Sci. 2014;79(2):S238-45. https://doi.org/10.1111/1750-3841.12342.

122. Huang AL, Chen X, Hoon MA, Chandrashekar J, Guo W, Tränkner D, et al. The cells and logic for mammalian sour taste detection. Nature. 2006;442:934-8. https://doi.org/10.1038/ nature 05084.

123. Kawaguchi H, Yamanaka A, Uchida K, Shibasaki K, Sokabe T, Maruyama Y, et al. Activation of polycystic kidney disease-2-like 1 (PKD2L1)-PKD1L3 complex by acid in mouse taste cells. J Biol Chem. 2010;285(23):17277-81. https://doi.org/10.1074/jbc. C110.132944.

124. Ishimaru $\mathrm{Y}$, Inada $\mathrm{H}$, Kubota $\mathrm{M}$, Zhuang $\mathrm{H}$, Tominaga $\mathrm{M}$, Matsunami H. Transient receptor potential family members PKD1L3 and PKD2L1 form a candidate sour taste receptor. Proc Natl Acad Sci. 2006;103(33):12569. https://doi.org/10. 1073/pnas.0602702103.

125. Haase L, Green E, Murphy C. Males and females show differential brain activation to taste when hungry and sated in gustatory and reward areas. Appetite. 2011;57(2):421-34. https://doi.org/10. 1016/j.appet.2011.06.009

126. Hoogeveen HR, Dalenberg JR, Renken RJ, ter Horst GJ, Lorist MM. Neural processing of basic tastes in healthy young and older adults — an fMRI study. NeuroImage. 2015;119:1-12. https://doi. org/10.1016/j.neuroimage.2015.06.017.

127. Frings S. The sour taste of a proton current. Proc Natl Acad Sci. 2010;107(51):21955. https://doi.org/10.1073/pnas.1016810108.

128. Deloose E, Corsetti M, Van Oudenhove L, Depoortere I, Tack J. Intragastric infusion of the bitter tastant quinine suppresses hormone release and antral motility during the fasting state in healthy female volunteers. Neurogastroenterol Motil. 2018;30(1). https:// doi.org/10.1111/nmo.13171.

129. Iven J, Biesiekierski JR, Zhao D, Deloose E, O'Daly OG, Depoortere I, et al. Intragastric quinine administration decreases hedonic eating in healthy women through peptide-mediated gutbrain signaling mechanisms. Nutr Neurosci. 2018:1-13. https:// doi.org/10.1080/1028415X.2018.1457841.

130. Meyer-Gerspach AC, Suenderhauf C, Bereiter L, Zanchi D, Beglinger $\mathrm{C}$, Borgwardt $\mathrm{S}$, et al. Gut taste stimulants alter brain activity in areas related to working memory: a pilot study. Neurosignals. 2016;24(1):59-70. https://doi.org/10.1159/ 000442612 .

131. Höfer D, Püschel B, Drenckhahn D. Taste receptor-like cells in the rat gut identified by expression of alpha-gustducin. Proc Natl Acad 
Sci U S A. 1996;93(13):6631-4. https://doi.org/10.1073/pnas.93. 13.6631.

132. Sutherland K, Young RL, Cooper NJ, Horowitz M, Blackshaw LA. Phenotypic characterization of taste cells of the mouse small intestine. Am J Physiol Gastrointest Liver Physiol. 2007;292(5): G1420-8. https://doi.org/10.1152/ajpgi.00504.2006.

133. Egan JM, Margolskee RF. Taste cells of the gut and gastrointestinal chemosensation. Mol Interv. 2008;8(2):78-81. https://doi.org/ 10.1124/mi.8.2.5

134. Iwatsuki K, Uneyama H. Sense of taste in the gastrointestinal tract. J Pharmacol Sci. 2012;118(2):123-8. https://doi.org/10.1254/jphs. 11R08CP.

135. Breer H, Eberle J, Frick C, Haid D, Widmayer P. Gastrointestinal chemosensation: chemosensory cells in the alimentary tract. Histochem Cell Biol. 2012;138(1):13-24. https://doi.org/10. 1007/s00418-012-0954-z.

136. Depoortere I. Taste receptors of the gut: emerging roles in health and disease. Gut. 2014;63(1):179-90. https://doi.org/10.1136/ gutjnl-2013-305112.

137.• Steensels S, Depoortere I. Chemoreceptors in the Gut. Annu Rev Physiol. 2018;80:117-41. https://doi.org/10.1146/annurevphysiol-021317-121332 Gut taste receptors communicate appetite-related information to the brain, thus taste perception may be influenced by gut function. Disruptions and adaptations in gut-brain signaling mechanisms may pave way for discovery of novel gut-based therapeutic targets in obesity

138. Deloose E, Janssen P, Corsetti M, Biesiekierski J, Masuy I, Rotondo A, et al. Intragastric infusion of denatonium benzoate attenuates interdigestive gastric motility and hunger scores in healthy female volunteers. Am J Clin Nutr. 2017;105(3):580-8. https://doi.org/10.3945/ajen.116.138297.

139. Hao S, Sternini C, Raybould HE. Role of CCK1 and Y2 receptors in activation of hindbrain neurons induced by intragastric administration of bitter taste receptor ligands. Am J Phys Regul Integr Comp Phys. 2008;294(1):R33-8. https://doi.org/10.1152/ajpregu. 00675.2007.

140. Zhang Y, Ji G, Xu M, Cai W, Zhu Q, Qian L, et al. Recovery of brain structural abnormalities in morbidly obese patients after bariatric surgery. Int J Obes. 2016;40(10):1558-65. https://doi.org/ 10.1038/ijo.2016.98.

141. Karlsson HK, Tuulari JJ, Tuominen L, Hirvonen J, Honka H, Parkkola R, et al. Weight loss after bariatric surgery normalizes brain opioid receptors in morbid obesity. Mol Psychiatry. 2016;21(8):1057-62. https://doi.org/10.1038/mp.2015.153.

142. Lepping RJ, Bruce AS, Francisco A, Yeh HW, Martin LE, Powell $\mathrm{JN}$, et al. Resting-state brain connectivity after surgical and behavioral weight loss. Obesity (Silver Spring). 2015;23(7):1422-8. https://doi.org/10.1002/oby.21119.

143. Wiemerslage L, Zhou W, Olivo G, Stark J, Hogenkamp PS, Larsson EM, et al. A resting-state fMRI study of obese females between preand postprandial states before and after bariatric surgery. Eur J Neurosci. 2017;45(3):333-41. https://doi.org/10.1111/ejn.13428.
144.• Shechter A, Schwartz GJ. Gut-brain nutrient sensing in food reward. Appetite. 2018;122:32-5. https://doi.org/10.1016/j.appet. 2016.12.009 Nutrient reinforcement or flavor-nutrient preference conditioning is mediated by neurochemical and hormonal signaling mechanisms along the gut-brain axis. Better understanding of physiological and neurochemical processes in appetition may lead to development of novel therapeutic, pharmacological targets for eating disorders and obesity.

145. Ackroff K, Yiin YM, Sclafani A. Post-oral infusion sites that support glucose-conditioned flavor preferences in rats. Physiol Behav. 2010;99(3):402-11. https://doi.org/10.1016/j.physbeh.2009.12. 012.

146. Ackroff K, Sclafani A. Oral and postoral determinants of dietary fat appetite. In: Montmayeur JP, le Coutre J, editors. Fat detection: taste, texture, and post ingestive effects. Boca Raton (FL): CRC Press/Taylor \& Francis; 2010. Chapter 12.

147. Uematsu A, Tsurugizawa T, Kondoh T, Torii K. Conditioned flavor preference learning by intragastric administration of Lglutamate in rats. Neurosci Lett. 2009;451(3):190-3. https://doi. org/10.1016/j.neulet.2008.12.054.

148.• Feeney EL, Leacy L, O'Kelly M, Leacy N, Phelan A, Crowley L, et al. Sweet and umami taste perception differs with habitual exercise in males. Nutrients. 2019;11(1):E155. https://doi.org/10. 3390/nu11010155 Habitual exercise associated with increased perception of umami and sweet taste intensity and lower hedonic rating to umami and sweet taste pleasantness. While habitual exercise did not influence percent energy intake, exercise-induced changes in taste perception may better inform the incorporation of exercise into personalised nutritional and dietary interventions.

149. Miguet M, Fillon A, Khammassi M, Masurier J, Julian V, Pereira $\mathrm{B}$, et al. Appetite, energy intake and food reward responses to an acute high intensity interval exercise in adolescents with obesity. Physiol Behav. 2018;195:90-7. https://doi.org/10.1016/j.physbeh. 2018.07.018.

150. Jastreboff AM, Sinha R, Arora J, Giannini C, Kubat J, Malik S, et al. Altered brain response to drinking glucose and fructose in obese adolescents. Diabetes. 2016;65(7):1929-39. https://doi.org/ $10.2337 / \mathrm{db} 15-1216$.

151. Connolly L, Coveleskie K, Kilpatrick LA, Labus JS, Ebrat B, Stains J, et al. Differences in brain responses between lean and obese women to a sweetened drink. Neurogastroenterol Motil. 2013;25(7):579-e460. https://doi.org/10.1111/nmo.12125.

152. Wang J, Sun X, Yang QX. Methods for olfactory fMRI studies: implication of respiration. Hum Brain Mapp. 2014;35(8):361624. https://doi.org/10.1002/hbm.22425.

153. Zhang Z, Zhang B, Wang X, Zhang X, Yang QX, Qing Z, et al. Altered odor-induced brain activity as an early manifestation of cognitive decline in patients with type 2 diabetes. Diabetes. 2018;67(5):994-1006. https://doi.org/10.2337/db17-1274.

Publisher's Note Springer Nature remains neutral with regard to jurisdictional claims in published maps and institutional affiliations. 